\title{
Tackling inequalities in health: the Australian experience
}

\author{
Margaret Whitehead, Ken Judge, David J Hunter, Robert Maxwell, Mary Ann Scheuer
}

Federal and state governments in Australia have embarked on a series of national initiatives which show a firm commitment to tackling social inequalities in health. The development of national goals and targets for health, for example, covers social and environmental conditions and sets differential targets for specific social groups with very poor health status. In a complementary initiative, a wide ranging analysis of the health care system-the National Health Strategy-has as one of its main objectives to improve the equitable impact of the health system. Where problems of access to and quality of services have been exposed, policies have been devised to deal with them. The exceptionally poor health of the Aboriginal community has elicited cross party support for action. Resources have been allocated to implement the National Aboriginal Health Strategy: to improve living and working conditions, education, and employment opportunities. Britain can glean much from the Australian experience.

For over a decade the medical and nursing professions in Britain have taken a leading role in calling for a clearer national commitment to tackling social inequalities in health. ${ }^{1-4}$ Sadly, these calls have not been heeded because in the United Kingdom this has been seen as a party political issue instead of an important pointer to priorities for action.

The latest missed opportunity on this front was the 1992 Health of the Nation English health strategy, issued by the Department of Health. ${ }^{5}$ This said practically nothing to stimulate action in relation to the systematic health differentials between social groups in Britain. Yet nobody, of whatever political party, can seriously want these differentials to continue if they can be changed.

What might a "national commitment" look like, and how might the rhetoric of concern for inequalities be translated into concrete action? Recent developments in Australia suggest that in some respects that country is further along the road than Britain in formulating a policy response to the obvious inequalities found there. Australian initiatives are therefore worth closer inspection.

\section{Stark contrasts}

Australia can be described as one of the healthiest countries in the world, but also one with some of the most dramatic social inequalities in health. In 1990 the expectation of life at birth stood at 80 years for women and 73.9 years for men, higher than that expected in New Zealand, the United States, and the United Kingdom. In the same year infant mortality was 8.2 deaths per 1000 live births, comparable with countries such as Norway and the United Kingdom. Other measures of health show promising improvements. ${ }^{6}$

Yet huge inequalities in health exist between different social groups within the population. The most striking differences are to be found between Aborigines and the Australian population as a whole. For example, expectation of life at birth for Aborigines is some $15-17$ years less than that for the total Australian population, and infant mortality is three

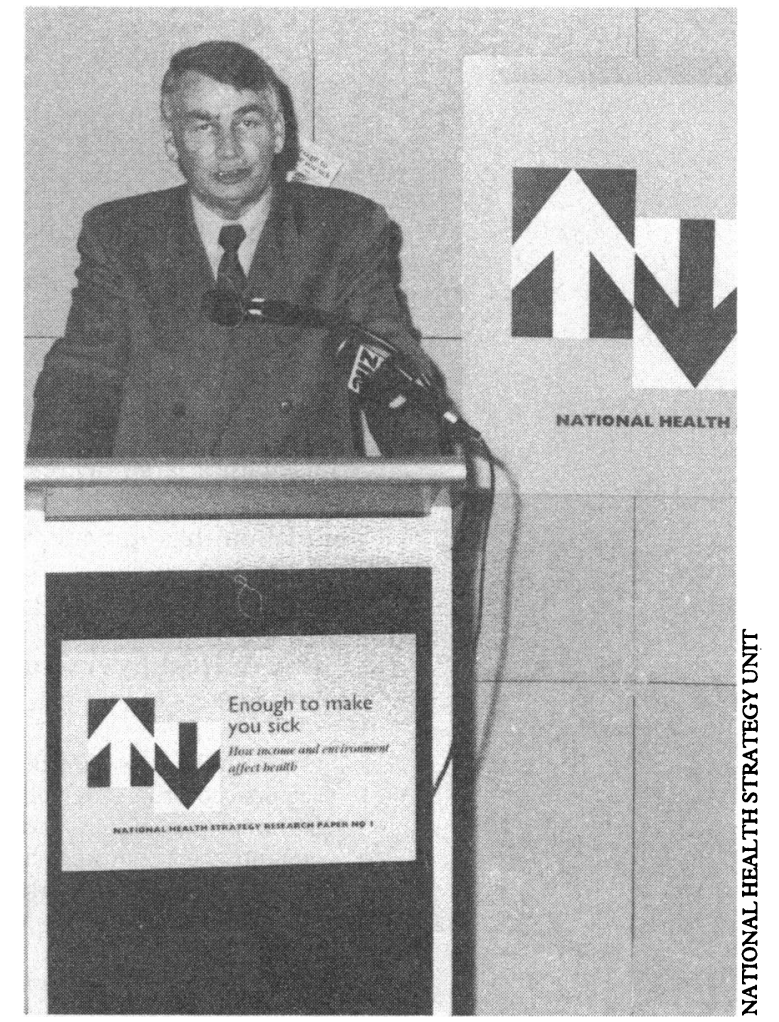

Brian Howe, deputy prime minister at the time, launches Australia's "Black report"

times greater. Differences in adult mortality reach a peak for the 35-44 year age group, with Aboriginal men dying at a rate more than 11 times that of the total male population. Aboriginal women in that age group have death rates around nine times those of the total female population. ${ }^{6}$

Aborigines form a relatively small subgroup of the population $(1 \cdot 4 \%)$. Substantial differentials can, however, be observed if comparing the top $20 \%$ of the population with the bottom $20 \%$ on a scale of "occupational prestige." For example, men in the lowest $20 \%$ of the population on this scale have death rates almost double those of the top $20 \%$. Using equivalent family income, the poorest third of working age men reported $65 \%$ more serious chronic illness than the richest third, and for women there was a $33 \%$ difference between rich and poor.

The Australian health care system is immensely complex, at least to outsiders. A universal system of health insurance known as Medicare, funded from general taxation, was introduced in 1984 . All residents of Australia are eligible for benefits under the scheme, and services are provided on a fee for service basis. In primary care a national schedule of fees has been established. Patients are reimbursed for $85 \%$ of the schedule fee for each item of general practitioner service and for specialist consultations outside hospitals. Diagnostic services attract lower benefits, while some services provided by professions allied to medicine are not covered by Medicare. Doctors do not have to stick to the schedule fee but can choose to bill the Medicare administration directly, rather than the 
patient. If they do this, the doctor is paid the $85 \%$ of the fee covered by Medicare and the patient pays nothing. This bulk billing, as it is called, is becoming increasingly common, with $70 \%$ of bills for general practitioners' services settled accordingly.

For secondary care there is a mix of public, private, and charitable hospitals. About $40 \%$ of funding for the public hospitals comes from the federal government, nearly $50 \%$ from state governments, and the remainder from private health insurance. The public hospitals are managed by the states, and the federal government has very little direct say in them. For hospital services the Medicare benefit is only $75 \%$ of the schedule fee, but patients can insure privately to cover the gap between benefit and fee. In practice, people who choose to be public patients in public hospitals pay nothing and the hospital receives a capped grant to provide these services. People who choose to be private patients in public hospitals have $75 \%$ of the schedule fee reimbursed by Medicare and pay any additional fees through private insurance, if they have it.

Since the introduction of Medicare in 1984 the proportion of the population covered by private insurance has dropped from $62 \%$ in 1983 to $42 \%$ in 1992 , with a large decrease in coverage among young people. ${ }^{7}$ In contrast, in Britain only about $11 \%$ of the population has private insurance ${ }^{8}$ and coverage is

\section{Box A: Healthy environments: goals and targets ${ }^{12}$}

Goals and targets have been developed in six separate sectors covering the physical environment (global pollution, air, water, and soil contamination, indoor environment); housing, homes and community infrastructure; transport; work and the workplace; schools; and health care settings.

An example: adequate housing

Goal: To increase the number of people living in adequate housing

\section{Proposed targets:}

PRIORITY POPUlATION-Aboriginal and Torres Strait Islanders in rural communities and settlements

To reduce exposure to risks to health associated with poor living conditions.

Intermediate indicator--to increase the proportion of Aboriginal and Torres Strait Islanders living in remote and rural communities who live in dwellings which have

- Potable water for drinking/cooking

- Adequate water supply

- Electricity

- Bathing and laundry facilities

- Sewage disposal facilities

- Waste disposal

- Adequate drainage.

Baseline-to be derived from ATSIC study into housing and community infrastructure.

PRIORITY POPULATION - low income private tenants

To reduce exposure to health risks associated with poor living conditions.

Intermediate indicator - to reduce the proportion of low income tenants living in substandard accommodation.

Baseline - to be derived from ABS housing survey in 1994. restricted to a limited range of medical services. A special feature of the Australian system is compulsory community rating. In this, insurers have to pool good and bad risks and charge a standard premium to all subscribers. One problem is that as younger, fitter people have dropped out of the pool, premiums have had to rise dramatically.

\section{Setting goals and targets}

Against this background, several policy initiatives suggest that the issue of inequalities in health has been taken seriously in Australia. For example, tackling inequalities has been an aim of successive Australian efforts to set national goals and targets for health. Considerable advances have been made compared with other countries.

As early as 1985 the Better Health Commission was set up to report on the current health status of the Australian population and to identify underlying health problems and strategies for dealing with them. An early report from the commission stated that: "in determining health needs and priorities for action, the inequalities in health due to social, economic and environmental factors must be recognised, and, when possible, addressed." 9

Following the commission's recommendations, ${ }^{10}$ the Health Targets and Implementation Committee was set up by the state and federal health ministers to develop national goals and targets. Its report, Health for All Australians, published in 1988, also emphasised the importance of wider determinants of health and of reducing inequalities, though it was not able to set goals and targets in these areas at that time. "Like the Better Health Commission, it concentrated on targets for preventable mortality and behavioural risk factors. In 1991, however, a year long review and revision of existing targets was initiated, and the results were published in February 1993. ${ }^{12}$

These latest goals and targets have been used to make more explicit the challenge of achieving greater equity in health. This is done in two ways: by setting specific targets for disadvantaged population groups and by spelling out the need to change key determinants of health beyond the health care sector. Proposals on these key determinants range from targets to improve overall literacy, employment, and housing through to describing the unequal health impact of the physical environment on different social groups. Box $A$ lists the sectors covered under the heading of "healthy environments" and gives an illustration of goals and targets for certain Aboriginal communities and for low income private tenants. In contrast, most countries, including England, ${ }^{5}$ have set universal targets which run the risk of masking important health differentials.

The way in which the goals and targets were developed in Australia also differs noticeably from the English experience, where the whole process was controlled from within the Department of Health. In Australia a group of academics acted as consultants to the federal Department of Health, Housing, and Community Services and were given the freedom to consult and encourage participation by as wide a range of people as possible. Formulation of each target involved many people and agencies with experience in the relevant sectors. They linked in, for example, with Aboriginal community leaders working on the National Aboriginal Health Strategy and with the housing and transport sector during the development of the healthy environment targets.

The target setting exercise has already had modest success in convincing ministers to incorporate some of the goals and targets in the five yearly hospital funding agreement drawn up between state and federal governments. All state and federal health ministries 
will also be required to review their work in the light of these goals and targets. Though a bold start, the exercise has still to tackle the problems of how the targets are to be achieved or the deeper involvement of other sectors with an influence on the key determinants of health. In this respect it is at a similar stage to the British initiative.

\section{National strategy}

A complementary development has been the National Health Strategy initiative..$^{13}$ This is a two year review and strategy development programme set up in November 1990 by the deputy prime minister, Brian Howe. He took over the health brief with a reputation as a social policy reformer, having previously reviewed the social security system with the aim of making it fairer. He replaced a health minister who had been widely regarded as extremely successful in increasing access to health services through the introduction of Medicare. Nevertheless, new problems of access were appearing on the horizon, as were issues of cost containment. These concerns, together with the need for the new minister to make his mark, resulted in Howe commissioning a wide ranging analysis of the health care system.

Box $B$ summarises the terms of reference of the strategy initiative. Attention was not restricted to curative and caring services but extended to activities fostering good health, including health education, promotion and public health. From the beginning, the importance of considering equity issues was emphasised by the director of the strategy unit, Jenny Macklin:

One major objective will be to improve the equitable impact of the health system. As poor health is linked to socio-economic circumstances, the strategy will work to reduce inequalities in terms of cost, access and health status. Options for change in other areas to be covered by the Strategy will be analysed to ensure that any changes maintain or improve equity. ${ }^{13}$

Equity was seen primarily in terms of access to services on the basis of need rather than social status, and financing of services according to means. As the initiative has progressed, some undoubted strengths of having a national commitment of this nature have emerged. There is clearly an advantage in having the initiative linked to the political process at federal level, with the personal backing of the deputy prime minister, and with a director, Jenny Macklin, possessing respected political and analytical skills. This has guaranteed not only resources but also access to national databases not always open to others. It has also ensured that some of the proposals, particularly those concerned with improving access to health services, have been incorporated into the federal budget plans for 1992-3 and the five yearly hospital funding agreements between state and federal governments.

Another strength of the initiative has been the sophisticated analyses it has been able to produce. Eleven background papers and four major issues papers have been prepared in this way. True to the director's stated objective, all the analyses and policy options stemming from them have paid attention to the effects of the various proposals on access to services and costs borne by patients. The strategy unit has marshalled the efforts of several Australian research groups to carry out new analyses on socioeconomic factors. From this work, a substantial research report was published in September 1992 on how income and environment affect health, ${ }^{14}$ on a scale and depth approaching that of the Black report in Britain. ${ }^{15}$ Unlike the Black report, however, the Australian document received official blessing, launched by the deputy prime minister himself. The report concludes
Box B: National Health Strategy: summary of terms of reference ${ }^{13}$

To analyse evidence and provide strategy options concerned with

- Demand for medical services

- Delivery of services

- Financing of services and its effect on effective health care delivery

- Distribution of health costs across the population and their impact on individuals and families

- The role of the private sector

- The balance between supply and demand of health workers

- Methods to stimulate an increased focus on preventive services and the integration of these services with primary and secondary care

that, in addition to making health services more equitable, policy needs to be focused on five broad areas: the distribution of economic resources; education; living conditions; access to and conditions of work; and the provision of social support.

It is too early to say what the government response will be to this report in terms of committing resources and policy initiatives. But it has already had an impact and led to some innovative developments at other levels-for example, on the need to improve working conditions and workplace reform. The strategy unit has been engaged in raising awareness and educating managers and trade unionists all over Australia. A national workshop on the issue brought together management and union representatives, and similar activities have taken place in each state. The aim of the exercise is to encourage commitment to reform of working arrangements, so that joint work on practical strategies could then begin.

One proposal, put forward and agreed by participants at the national workshop, was the establishment of a "best practice" programme to which agencies could apply for funds to redesign work. Guidelines have been agreed by management and union representatives and have been put to federal ministers. In the meantime, the government of Western Australia has started such a scheme. Funds have been allocated to facilitate workplace reform and the unions in Western Australia have put forward a job redesign package as part of their current wage discussions.

Another innovation has been in the area of public participation. The strategy unit employed the Australian Council of Social Services and the Consumer Health Forum to conduct a "consultation on health inequalities" around Australia. Focus group discussions were held with Aborigines, people with disabilities, lone parents, consumer advocates, and other special needs groups. This was an attempt to gather the views of people who are often underrepresented in formal consultation processes.

The possible long term influence of the National Health Strategy is difficult to predict. It needs time to develop its policies on tackling inequalities in health, but with the Australian general election on the 13 March, its days may be numbered. This is one of the dangers of its strong political ties to one party and one politician in particular.

\section{Improving access}

The National Health Strategy initiative has been particularly valuable in documenting the evidence on inequalities in access to and quality of healthcare. The introduction of Medicare in 1984 improved access to 
services, but underlying problems remain. Two examples illustrate some of the dilemmas the strategy has exposed and the policies initiated to deal with them.

Firstly, although every Australian 'has an equal right to be treated in a public hospital, the income that can be derived from treating a privately insured patient is greater than that for treating a public patient in the same facilities. Fees can be obtained from Medicare and topped up with private insurance. This incentive, combined with a period of cost containment in which public hospital funding from state and federal governments has been under increasing pressure, has created even more of a temptation to attract privately funded patients in preference to patients solely supported by public funds.

In these circumstances, there is evidence to suggest that patients are sometimes selected on the basis of insurance status rather than need. In 1990, for example, $73 \%$ of all acute hospital beds were public, but only $61 \%$ of total hospital bed days for acute services were allocated to public patients. ${ }^{16}$ There is also evidence that privately insured patients are being offered a higher quality of clinical service in public hospitals in terms of shorter waiting times for elective surgery and in gaining the attention of more experienced doctors. ${ }^{16}$ In an attempt to deal with this discrimination against public patients, the 1992-3 federal budget plan is introducing bonus payments to those states which increase the proportion of public patients treated. ${ }^{17}$ There are also penalties that will apply if the proportion falls below a particular level. The aim is to ensure that state governments and hospitals do not have a financial incentive to take private patients over public patients. An additional $£ 600 \mathrm{~m}$ ( $\$ \mathrm{~A} 1.36 \mathrm{bn}$ ) over five years has been allocated for this.

Secondly, the strategy has identified that access to outpatient and non-urgent casualty services run by public hospitals also seems to be declining for public patients. State governments have been closing these hospital based services to help save money on their capped budgets, on the assumption that patients will be able to obtain such services in the community, funded by the open ended Medicare budget from the federal government. The problem is that the patient often has to pay a portion of the cost for the community based services. This puts services which used to be available free from the hospital out of reach of patients on low income and those with chronic health conditions who require multidisciplinary care. ${ }^{716}$

Now that the problem has been identified, federal and state health ministers have agreed in principle that this type of service should be a federal responsibility and discussions have started on the practicalities. It is assumed that if all medical services are the responsibility of one level of government, then there will be no perverse incentive to close outpatient departments and thereby shift the cost from state to federal funds.

\section{Tackling Aboriginal issues}

Heightened awareness of Aboriginal health inequalities, coupled with acknowledgement of how disadvantaged Aborigines are in other aspects of life, has elicited cross party support for action to improve the situation.

Policy development has come from two main sources. Firstly, a National Aboriginal Health Strategy ${ }^{18}$ has been developed by a 19 member working party, 14 of whom were leading members of the Aboriginal community. They undertook exhaustive consultation with Aboriginal people and others to involve them in the policy formulation. Secondly, a royal commission, originally set up in 1987 to investigate the alarmingly high rates of Aboriginal deaths in police and prison custody, expanded its brief to become a wide ranging inquiry into the conditions under which Aboriginal and Torres Strait Islander communities live. ${ }^{19}$

Recommendations from these two sources were in broad agreement on what was needed: improvements in living and working conditions, better educational and employment opportunities, improved access to and quality of services, control by the Aboriginal community over services, and a say in making policies that affect them. There were also calls for better information systems to monitor conditions.

In response to the National Aboriginal Health Strategy the federal government has allocated an additional $£ 108 \mathrm{~m}$ ( $\$ \mathrm{~A} 232 \mathrm{~m}$ ) over a five year period from 1990 to 1995 . Three quarters of this is to be spent on improving housing, water supplies, sewage, roads, and communication networks to Aboriginal communities. The remainder is to establish community controlled health services and facilities and includes substance abuse, education, and prevention projects. The royal commission, reporting in 1991, noted that the money allocated was only one fifth of the estimated full cost of implementing the strategy and was therefore inadequate. ${ }^{19}$ The federal government's response to the royal commission's recommendations included allocating further resources for job creation and encouraging economic independence in Aboriginal communities. Recommendations on appointing representatives from Aboriginal communities to various local and national policy boards have been implemented.

A start has therefore been made on improving the social and economic conditions influencing Aboriginal health, but of course much more remains to be done. Perhaps the most interesting feature of the experience so far for Britain is to recognise the care with which the health problems of minority populations have been investigated and to some extent acted on.

\section{Conclusion}

There is certainly evidence, on paper, of a national commitment in Australia to reducing inequalities in health. In official pronouncements there is none of the reluctance found in Britain to acknowledge the existence of a problem and the need to deal with it. This can be seen in the setting of goals and targets, in the National Health Strategy, and in initiatives with the Aboriginal community. It is more difficult to judge how far the commitment has been translated into action, though it is clear that progress has been made in some areas. Britain has much to learn from the Australian experience.

The setting of goals and targets for health has advanced considerably in Australia, through focusing attention on specific social groups in the population with very poor health and through formulating targets for the wider social and environmental determinants of health. Although discussions about translating targets into action plans are at a preliminary stage, the succession of target setting exercises has been based on a broad concept of the influences on health. This is essential for successfully addressing inequalities in health. The Welsh Health Planning Forum has developed differential targets along these lines for the NHS in Wales, ${ }^{20}$ but in general the rest of the United Kingdom has not progressed so far. Local and national Health of the Nation initiatives would benefit considerably from such an approach.

One of the strengths of the Australian National Health Strategy initiative has been its "equity audit" on the health care sector-identifying problems over access and use of services for different groups in the population. The initiative has also made concerted attempts to tackle these problems. Whether the action 


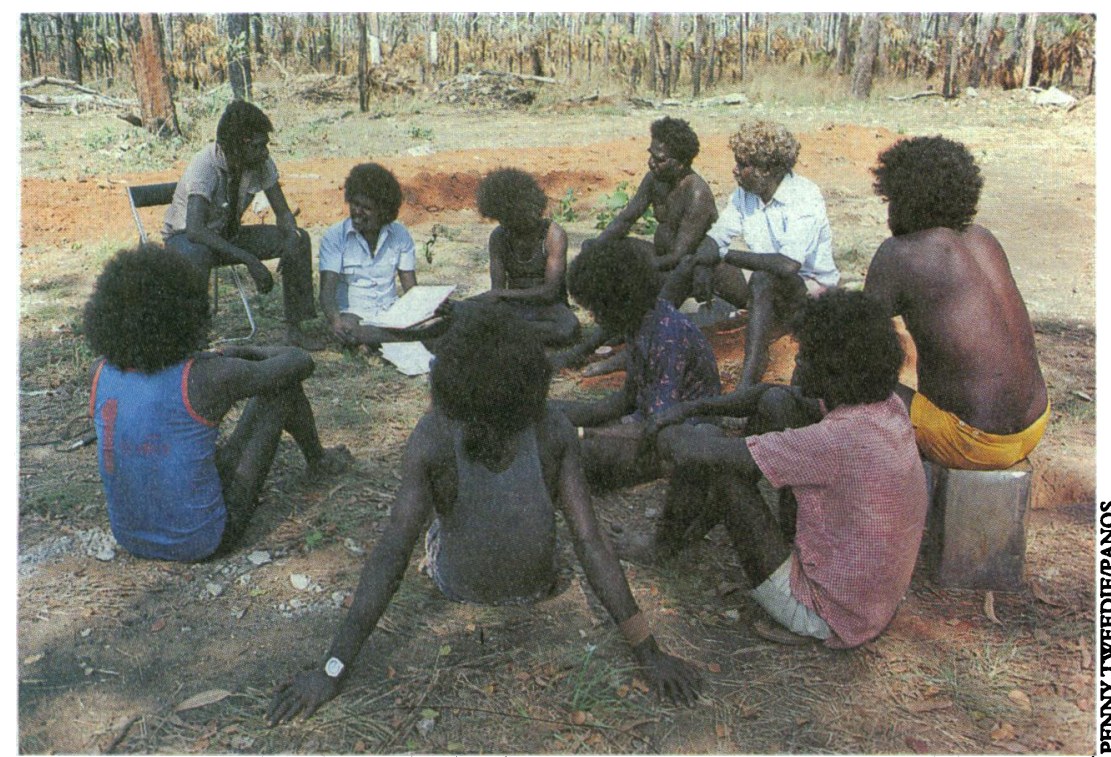

Aboriginal communities have been so disenfranchised in the past that giving them $a$ say in policies and decisions affecting them is seen as a ketement in improving their health

proposed will solve them is another matter. The analyses by the strategy unit revealed difficulties in maintaining the principle of access to services on the basis of need, against incentives to select patients on the basis of their insurance status. In Britain we are likély to come up against similar, if not identical, perverse incentives as the NHS reforms alter the way in which services are funded. For example, there have already been reports of hospitals giving preference. to patients of fundholding general practitioners. Continued vigilance will be necessary to monitor and to protect the principle that patients should have access on clinical rather than financial grounds.

The example of cost shifting between federal and state governments reveals how services for low income patients can inadvertently disappear in such a process. In Australia the scope for cost shifting of this nature may Be greater than in Britain, but it still goes on here. For example, savings on capped hospital drug budgets may be made by transferring costs to the more open ended general practice budget when discharging patients. Savings by the NHS have been made by switching funding for respite care and long stay nursing care to the social security budget. The basic problem with this shift is that previously free NHS services have become means tested services along the way. New funding arrangements for community care will not necessarily put a stop to such perverse incentives and may indeed provide further scope for cost shifting. The Australian experience provides a timely reminder of the importance of monitoring the effects of reforms on different social groups.

The Australians show considerable inventiveness in involving other sectors and groups in policy development. Indeed, the Aboriginal communities have been so disenfranchised in the past that giving them a say in decisions and policies affecting them is seen as a key element in improving their health. It looks as though this is being done in a serious, not just a token, way. This is something that has been advocated for disadvantaged communities across Europe but rarely gets past the rhetoric stage.

Health inequalities in Britain remain pervasive. If they are to be taken more seriously and tackled effectively in the future, there is much of practical value to be gleaned from the Australian experience.

The authors were all members of a King's Fund Institute group which visited Australia in the spring of 1992 to investigate the work of the National Health Strategy Initiative.

1. British Medical Association. Deprivation and ill-health. London: BMA, 1987 2 Faculty of Community Medicine. Equity: a prerequisite for health. Proceedings of the 1987 summer scientific conference of the Royal Colleges of Physicians of the $U K$ in collaboration with WHO. London: FCM, 1988.

3 Health Visitors Association. Building a healthy Britain: an HVA response to the Health of the Nation consultative paper. London: HVA, 1991.

4 Royal College of Nursing. A manifesto for health. London: RCN, 1991.

5 Department of $\mathrm{Health}$. The health of the nation. London: HMSO, 1992.

6 Australian Institute of Health and Welfare. Australia's health 1992. Canberra: Australian Government Publishing Service, 1992.

7 Wilcox S. A healthy risk? Use of private health insurance. Melbourne: National Health Strategy Unit, 1991. (Background paper No 4.)

8 Laing W. Going private. Independent health care in London. London: King's Fund, 1992.

9 Better Health Commission. Interim repon. Canberra: Australian Government Publishing Service, 1986

0 Better Health Commission. Looking forward to better health. Canberra: Australian Government Publishing Service, 1986.

1 Health Targets and Implementation Committee. Health for all Australians. Report to the Australian Health Ministers' Advisory Council and the Australian Health Ministers' Conference. Canberra: Australian Government Publishing Service, 1988.

12 Nutbeam D, Wise M, Bauman A, Harris E, Leeder S. Goals and targets for Australia's health to the year 2000 and beyond. Canberra: Australian Government Publishing Service, 1993.

13 Macklin J. The National Health Strategy: setting the agenda for change. Melbourne: National Health Strategy Unit, 1990.

14 National Health Strategy. Enough to make you sick: how income and environment affect health. Melbourne: National Health Strategy Unit, 1992. (Research paper No 1.)

15 Black D, Morris JN, Smith C, Townsend P. The Black report. In: Townsend $\mathrm{P}$, Whitehead M, Davidson N, eds. Inequalities in health. London: Penguin, 1992

16 National Health Strategy. Hospital services in Australia-access and financing. Melbourne: National Health Strategy Unit, 1991. (Issues paper No 2.)

17 Department of Health, Housing and Community Services. 1992-93 budget related paper No 8: health care for all Australians: 1992-93 reforms. Canberra: Australian Government Publishing Service, 1992.

18 National Aboriginal Health Strategy Working Party. A national Aboriginal health strategy. Canberra: National Aboriginal Health Strategy Working Party, 1989.

19 Royal Commission into Aboriginal Deaths in Custody. National report. Canberra: Australian Government Publishing Service, 1991.

20 Welsh Health Planning Forum. Protocol for investment in health gain: maternal and early child health. Cardiff: Welsh Office NHS Directorate, Welsh Health Planning Forum, 1991.

(Accepted 1 March 1993)

\section{Aberdeen considers academic rationalisation}

"The two colleges at Aberdeen, though situated within a mile of each other, are distinct Universities, in which the same sciences are taught by two sets of Professors. . . . If these two Universities were united in one, one set of Professors would become unnecessary; and as the present incumbents chose to retire, or were removed by death, their salaries might be applied to the purpose of establishing new professorships for teaching those sciences which at present are not taught here at all. In this way, in the course of a few years, the united University would become as complete in itself and as numerous as that of Glasgow, and Law Schools and Medical Schools might be introduced, both of which are now wanting; though at Aberdeen there is an Infirmary of very considerable magnitude. ..."

Sounds familiar to those who have followed the changes and proposals for the London medical schools and hospitals, but this was James Beattie, poet and professor of moral philosophy at Marischal College, Aberdeen, writing to a friend in 1786 . The proposed union of Marischal and King's Colleges did not take place till 1860. Planners be patient!

1 Forbes M. Beattie and his friends. Altrincham: Martin Stafford, 1990:218. (First published 1904.) 